RECyT

Año 23 / No 35 / 2021 / 6-13

\title{
Aislamiento e identificación de microorganismos amilolíticos y tolerantes a cianuro de efluentes de la industria almidonera
}

\section{Isolation and identification of amylolytic and cyanide tolerants microorganisms from cassava starch industry effluents}

\author{
Ramona C. Barua1', María A. Kolman¹, Marina S. Aguila¹, Pedro D. Zapata¹ y Adriana E. Alvarenga1, * \\ Laboratorio de Biotecnología Molecular. Instituto de Biotecnología Misiones. Facultad de Ciencias \\ Exactas, Químicas y Naturales. CONICET. Universidad Nacional de Misiones. \\ * E-mail: adrianaealvarenga@gmail.com \\ Recibido: 25/06/2020; Aprobado: 12/11/2020
}

\section{Resumen}

\begin{abstract}
El cultivo de mandioca en la Provincia de Misiones aporta la mayor parte de la producción a nivel nacional. Parte de la misma es destinada a la obtención de fécula, actividad que genera efluentes industriales con una elevada carga de materia orgánica y compuestos cianogénicos. Esto constituye una problemática a nivel ambiental y la biorremediación se presenta como una alternativa para la reducción de estos residuos, ya que se basa en la degradación del contaminante utilizando los microorganismos presentes en la matriz contaminada. El objetivo de este trabajo fue aislar microorganismos con capacidad para degradar almidón y tolerantes a cianuro a partir de efluentes de una industria almidonera. Fueron aisladas 93 cepas bacterianas y 15 de ellas fueron preseleccionadas mediante determinación cualitativa de actividad amilolítica. Utilizando el gen 16S rDNA para la identificación molecular, se determinó que algunos de estos aislamientos pertenecen a los géneros Pseudomonas, Acinetobacter y Proteus. Esas cepas se cultivaron en medio mínimo con distintas concentraciones cianuro y se logró determinar que una de ellas posee tanto la actividad amilolítica como la tolerancia a cianuro, ambas características deseables para biorremediación de efluentes de la industria almidonera.
\end{abstract}

Palabras clave: Mandioca; Bacterias; Almidon; Cianuro; Biorremediación.

\section{Abstract}

Cassava cultivation in the Misiones province largely contributes to the national production. Part of it is used to obtain starch, which generates industrial effluents with a high load of organic matter and cyanogenic compounds. This constitutes a problem at the environmental level and bioremediation is presented as an alternative to reduce this waste, since it is based on the degradation of the pollutant using microorganisms present in the contaminated matrix. The objective of this work was to isolate microorganisms with starch degradation capacity and tolerance to cyanide from effluents of the starch industry. We isolated 93 bacterial strains and 15 were preselected by qualitative determination of amylolytic activity. Using the 16S rDNA gene for molecular identification, it was determined that some of these isolates belong to the genera Pseudomonas, Acinetobacter and Proteus. These strains were cultivated in minimal medium with different cyanide concentrations and it was possible to determine that one of them has amylolytic activity and tolerance to cyanide, both desirable characteristics for bioremediation of effluents from the cassava starch industry.

Keywords: Cassava; Wastewater; Bacteria; Starch; Cyanide; Bioremediation.

\section{Introducción}

La mandioca (Manihot esculenta) es una planta nativa de Sudamérica cuyo tubérculo posee un elevado valor nutricional, siendo una importante fuente de carbohidratos [1]. En la provincia de Misiones, el cultivo de mandioca aporta un $70 \%$ de la producción a nivel nacional, siendo su principal destino el consumo fresco [2]. Sin embargo, un $25 \%$ de esta producción se utiliza para la obtención de fécula de mandioca destinada a la industria alimenticia, textil y papelera [3]. La fécula es obtenida a través de un proceso industrial que genera residuos sólidos y líquidos. Los principales residuos sólidos son la cáscara, una pequeña proporción de harina y un material fibroso denominado bagazo compuesto por un $30-40 \%$ de almidón que puede ser utilizado en procesos microbiológicos para la obtención productos de valor [4]. Por otro lado, los residuos líquidos contienen agua, almidón, fibra, minerales y compuestos 
cianogénicos. La descarga directa de estos efluentes en una corriente de agua produce una caída muy importante en el oxígeno disuelto debido a la presencia de materia orgánica en exceso [5]. Por otra parte, uno de los componentes de estos residuos es un glucósido denominado linamarina cuya hidrólisis da como resultado glucosa, acetona y ácido cianhídrico que es altamente tóxico [6] por lo que la eliminación de los efluentes sin tratamiento pone en riesgo los ecosistemas acuáticos y la salud humana. Normalmente, las fábricas de fécula procesan sus efluentes utilizando lagunas de decantación como un paso que favorece la degradación aeróbica de los compuestos orgánicos. En la actualidad, la incorporación de un proceso adicional de tratamiento anaeróbico permite la producción de biogas a partir de esos efluentes y logra minimizar la toxicidad de ácido cianhídrico [7].

Una alternativa para el tratamiento de efluentes industriales es la biorremediación biológica. Este proceso se puede llevar a cabo mediante dos estrategias: la bioestimulación y la bioaumentación [8]. La primera, consiste en la adición de componentes que mejoren la actividad metabólica de los microorganismos presentes en el sitio contaminado, mientras que en la segunda se incorporan bacterias que sean capaces de eliminar ciertos compuestos tóxicos [8]. En ambos casos se presenta como desafío la prevalencia de los microorganismos cuya actividad fisiológica sea la indicada para el proceso de remediación. Por este motivo, es necesario conocer la diversidad de microorganismos presente en los efluentes para establecer las capacidades metabólicas in situ, ya sea para mejorar el proceso de bioestimulación o para seleccionar aquellos que serán reintroducidos a mayor escala en el ambiente contaminado [8]. Varios estudios han demostrado que existen bacterias y hongos que pueden metabolizar el cianuro como única fuente de nitrógeno y carbono para originar productos finales no tóxicos, tanto en ambientes aerobios como anaerobios, incluyendo Bacillus punillus, Pseudomonas fluorescens, Pseudomonas paucimobii, Pseudomonas pseudoalcaligenes, Leptosphaeria maculans, Fusarium oxysporum, Burkholderia cepacia, Trichoderma sp., Klebsiella oxytoca, Escherichia coli y Azotobacter vinelandii [9]. Por otro lado, además de compuestos cianogénicos, los residuos en los efluentes contienen un 55-60\% de almidón que permanece inseparable de las fibras de celulosa [10] y que podría actuar estimulando la producción de amilasas bacterianas $[11,12]$.

Dada la importancia de los microorganismos en los procesos de reducción de la carga orgánica en los efluentes de la industria almidonera, se plantea como objetivo de este trabajo el aislamiento y caracterización de bacterias con potencial para la degradación de compuestos cianogénicos, asimilación de cianuro y producción de amilasas, que podrían ser utilizadas en procesos de biorremediación.

\section{Materiales y Métodos}

\section{Muestras de efluentes}

Las muestras de efluentes provenían de una planta industrial almidonera local. Las mismas fueron colectadas en botellas de plástico de $500 \mathrm{~mL}$, mantenidas en frío y procesadas dentro de las 24 hs.

\section{Aislamiento de microorganismos}

Para el aislamiento de las bacterias se utilizó un medio mínimo con la siguiente composición: 1 g. $\mathrm{L}^{-1}$ $\mathrm{K}_{2} \mathrm{HPO}_{4} 2 \mathrm{H}_{2} \mathrm{O}, 0.2$ g.L $\mathrm{L}^{-1} \mathrm{MgSO}_{4} .7 \mathrm{H} 2 \mathrm{O}, 0.01$ g.L $\mathrm{L}^{-1} \mathrm{CaCl}_{2}$. $\mathrm{H}_{2} \mathrm{O}, 0.01$ g.L $\mathrm{L}^{-1} \mathrm{NaCl}, 0.2$ g.L $\mathrm{L}^{-1} \mathrm{MnSO}_{4} \cdot 4 \mathrm{H}_{2} \mathrm{O}, 0.2$ g.L $\mathrm{L}^{-1}$ $\mathrm{CuSO}_{4}$ y 0.2 g.L $\mathrm{L}^{-1} \mathrm{ZnSO}_{4} .7 \mathrm{H}_{2} \mathrm{O}$. Este medio fue suplementado con fécula de mandioca comercial (Medio Mínimo con Fécula de Mandioca, MMFM) o bagazo de mandioca provista por la almidonera (Medio Mínimo con Bagazo de Mandioca, MMBM) a una concentración de 2 g. $\mathrm{L}^{-1}$. Ambos medios fueron esterilizados en autoclave a $121^{\circ} \mathrm{C}$ por 15 min a $1 \mathrm{~atm}$. de presión. Luego, a cada uno se adicionó 10 $\mathrm{mL}$ de muestra y se incubó con agitación $150 \mathrm{rpm}$ a $30^{\circ} \mathrm{C}$ por $24 \mathrm{~h}$. Los cultivos fueron realizados por triplicado.

Una alícuota de la muestra fue también cultivada en medio Luria-Bertani (LB). Para ello, se utilizó $70 \mathrm{~mL}$ de la muestra del efluente y $30 \mathrm{~mL}$ de LB líquido, luego de 24 $\mathrm{h}$ se tomaron $50 \mathrm{~mL}$ de ese cultivo y se adicionaron a 50 $\mathrm{mL}$ de LB. Finalmente se adicionaron $30 \mathrm{~mL}$ del cultivo anterior a $70 \mathrm{~mL}$ de LB. Los cultivos se incubaron por 24 $\mathrm{h}$ a $30^{\circ} \mathrm{C}$ a $150 \mathrm{rpm}$.

La selección de las bacterias fue realizada por agotamiento de estría en medio sólido. Para el aislamiento, se realizaron diluciones seriadas 1:10 de cada uno de los cultivos en agua destilada estéril y se inocularon $0.1 \mathrm{~mL}$ en placas de Agar nutritivo (Britania) conteniendo Carbendazim como antifúngico $\left(0.5\right.$ g. $\left.\mathrm{L}^{-1}\right)$ para la obtención de colonias aisladas. Éstas fueron incubadas por $24 \mathrm{~h}$ a $28^{\circ} \mathrm{C} \mathrm{y}$ $37^{\circ} \mathrm{C}$. Los aislamientos se conservaron en LB con glicerol $(10 \%, \mathrm{v} / \mathrm{v}) \mathrm{a}-20^{\circ} \mathrm{C}$.

\section{Selección de cepas amilolíticas}

Las colonias de los microorganismos aislados previamente fueron inoculadas en placas de Petri divididas en cuadrantes conteniendo agar (12 g. $\left.\mathrm{L}^{-1}\right)$ con almidón soluble (10 g. $\left.\mathrm{L}^{-1}\right)$ a $\mathrm{pH} 7,0$ y $\mathrm{pH} 5,1$. Se inocularon por punción entre 22 a 24 aislamientos por placa y se incubaron a $28^{\circ} \mathrm{C}$ y $37^{\circ} \mathrm{C}$ durante $72 \mathrm{~h}$. Se realizaron dos repeticiones del ensayo con duplicados de cada placa. Posteriormente, cada placa fue cubierta con solución de iodo $1 \%(\mathrm{p} / \mathrm{v})$ durante 5 min y se seleccionaron los aislamientos cuyas colonias presentaron un halo de clarificación alrededor de las mismas indicando la hidrólisis del almidón. 


\section{Caracterización morfológica y fisiológica de cepas amilolíticas}

La caracterización macroscópica de los microorganismos aislados y seleccionados se realizó mediante los parámetros: forma, tamaño, elevación, margen, color, superficie, densidad y consistencia de las colonias desarrolladas en placas de Petri conteniendo Agar nutritivo (Britania). Para la identificación microscópica se llevó a cabo la tinción diferencial de Gram de cada aislado.

Para la prueba bioquímica convencional de la catalasa [13], sobre un portaobjetos se suspendió una pequeña cantidad de cultivo de bacteria con ansa ojal y con ayuda de una pipeta Pasteur se colocó una gota de agua oxigenada $(10 v)$, seguidamente, y según la detección de formación de burbujas, se clasificaron como catalasas positivas o negativas.

\section{Identificación molecular}

La extracción de ADN se realizó según la técnica descripta por Hoffman y Winston [14]. Se utilizó la técnica de reacción en cadena de la polimerasa (PCR) para amplificar un fragmento de $\sim 1500 \mathrm{nt}$ (nuceótidos), la región del DNA que codifica para el rRNA $16 \mathrm{~S}$, utilizando los cebadores sentido y antisentido, 27F y 1492R [15]. Los fragmentos amplificados se observaron mediante electroforesis en gel de agarosa, utilizando $4 \mu \mathrm{L}$ de producto amplificado y $2 \mu \mathrm{L}$ de solución Gel Red (Promega). La corrida electroforética se realizó a $110 \mathrm{~V}$ por 30 minutos en solución de tampón TBE 0.5\% (10 mM Tris-HCl, $10 \mathrm{mM}$ ácido bórico, $1 \mathrm{mM}$ EDTA). Los geles se observaron bajo luz UV.

Las secuencias obtenidas fueron alineadas utilizando ClustalW junto a secuencias del mismo género o similares disponibles en la base de datos National Center for Biotechnology Information (NCBI, https://www.ncbi.nlm.nih. gov/). El análisis filogenético fue inferido por el método Neighbor-Joining y las distancias evolutivas se calcularon utilizando el método de máxima verosimilitud compuesta con un soporte estadístico (Bootstrap) de 2000 réplicas para la construcción de árboles filogenéticos mediante el software MEGA X [16].

\section{Crecimiento de cepas amilolíticas}

Para determinar la tasa de crecimiento de los aislamientos que mostraron actividad amilolítica, se procedió a cultivarlas en tres medios:(i) medio mínimo con fécula de mandioca $1 \% \mathrm{p} / \mathrm{v}$, (ii) medio LB y (iii) medio LB con almidón soluble $1 \% \mathrm{p} / \mathrm{v}$.

Se prepararon preinóculos con una ansada proveniente de una placa en $10 \mathrm{~mL}$ del medio correspondiente que fueron incubados a $28^{\circ} \mathrm{C}$, con $200 \mathrm{rpm}$ de agitación durante 24 h. Luego de ese período, se tomó una alícuota de $1 \mathrm{~mL}$, se diluyó 1:100 y se midió la absorbancia a $600 \mathrm{~nm}$. Se realizó el cálculo correspondiente para determinar el volumen de preinóculo necesario para iniciar un cultivo con una absorbancia de 0.2. Estos cultivos fueron incubados a $28^{\circ} \mathrm{C}$ con agitación (200 rpm). Para realizar la curva de crecimiento se midió la absorbancia cada $1 \mathrm{~h}$ a partir de 1 $\mathrm{mL}$ de muestras. Luego de las $3 \mathrm{~h}$ de iniciada la curva las muestras fueron diluídas 1:100.

\section{Selección de cepas cianogénicas}

Los aislados bacterianos seleccionados por su actividad amilolítica fueron inoculados por el método de punción en placas que contenían medio mínimo agarizado suplementado con glucosa al $1 \%$ y cianuro en distintas concentraciones ( $5 \mathrm{mM}, 10 \mathrm{mM}, 20 \mathrm{mM}$ y $30 \mathrm{mM})$. Las placas fueron incubadas en estufa a $37^{\circ} \mathrm{C}$ por $24 \mathrm{~h}$.

\section{Resultados y discusión}

A partir de las muestras de efluente se realizaron 93 aislamientos bacterianos por agotamiento de estría en medio sólido. Utilizando el medio MMBM se aislaron 28 cepas a $28^{\circ} \mathrm{C}$ y 25 cepas a $37^{\circ} \mathrm{C}$. Con el medio de MMFM se aislaron 9 y 12 cepas a $28^{\circ} \mathrm{C}$ y $37^{\circ} \mathrm{C}$, respectivamente. Finalmente, en medio LB se aislaron 10 cepas a $28^{\circ} \mathrm{C}$, mientras que a $37^{\circ} \mathrm{C}$, se obtuvieron 11 aislamientos. Cada aislado fue nombrado mediante las siglas BAM (Bacterias Amilolíticas Misiones) y enumeradas (1-93). El número de aislamientos obtenidos en este trabajo puede relacionarse con la elevada carga de material orgánico presente en el efluente, lo que favorece el crecimiento bacteriano. En trabajos previos de análisis de comunidades bacterianas en efluentes de mandioca, se ha reportado que la carga bacteriana es alta, lo que indica una gran diversidad de microorganismos [17, 18].

En la determinación cualitativa de la actividad amilolítica (Tabla 1), se ha observado que cuando las bacterias crecieron a $28^{\circ} \mathrm{C}$ y $37^{\circ} \mathrm{C}$, tanto a $\mathrm{pH} 5$ como a $\mathrm{pH} 7$, el aislamiento BAM023 siempre se formó un halo de clarificación (Figura 1).

Tabla 1: Determinación cualitativa de actividad amilolítica. Condiciones de $\mathrm{pH}$ y temperatura en las que los aislados formaron halos de clarificación por producción de amilasas.

\begin{tabular}{|c|c|c|}
\hline $\mathbf{p H}$ & \multicolumn{2}{|c|}{ Temperatura } \\
\hline & $\mathbf{2 8 ^ { \circ } \mathbf { C }}$ & $\mathbf{3 7}^{\circ} \mathbf{C}$ \\
\hline \multirow{2}{*}{5,1} & BAM023 & BAM023 \\
& BAM028 & BAM028 \\
& BAM077 & BAM077 \\
\hline \multirow{2}{*}{7,0} & BAM023 & BAM023 \\
& BAM028 & BAM005 \\
& BAM077 & BAM020 \\
\hline
\end{tabular}




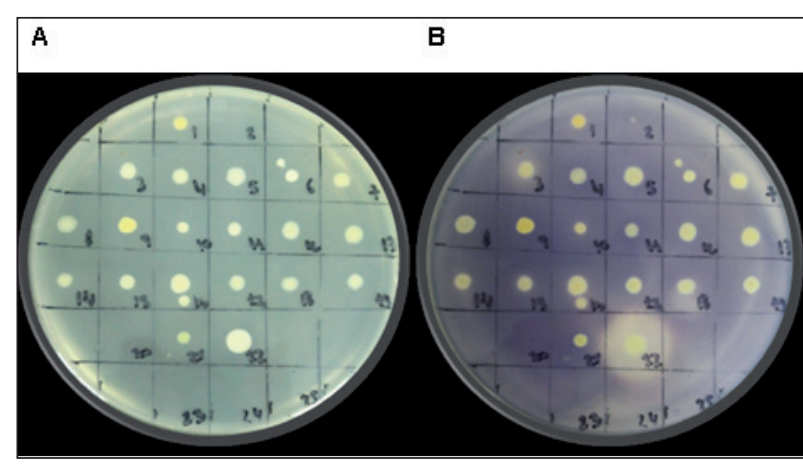

Figura 1: Determinación de actividad amilolítica. La actividad fue revelada mediante tinción con solución de iodo $1 \%$ a pH 7 y $37^{\circ} \mathrm{C}$. A) Placa inoculada sin tinción. B) Placa con tinción que presenta un pequeño halo de clarificación alrededor de la colonia desarrollada en el cuadrante 3 (BAM005), cuadrante 18 (BAM020) y un halo de mayor tamaño en cuadrante 22 (BAM023).

Si bien la proporción de aislamientos positivos para la actividad amilolítica es relativamente baja (5\% del total verificados) hay que tener en cuenta que las condiciones de cultivo, como la temperatura y el $\mathrm{pH}$, así también como la presencia de azúcares simples y fuentes de nitrógeno, pueden afectar la producción y actividad de las enzimas amilolíticas, [19].

Las características morfológicas de las 15 cepas observadas in vivo así como los resultados para la prueba bioquímica de la catalasa se detallan en la Tabla 2.

Tabla 2: Características morfológicas de los aislados bacterianos crecidos en placas de Petri con agar nutritivo, clasificación según tinción de GRAM y actividad catalasa.

\begin{tabular}{|c|c|c|c|}
\hline Colonia & Aspecto macroscópico & Catalasas & Tinción GRAM \\
\hline BAM 003 & $\begin{array}{l}\text { Crecimiento en césped, aspecto } \\
\text { traslúcido. El medio, inicialmente de } \\
\text { color miel, tornó a verde amarronado. }\end{array}$ & + & $\begin{array}{l}\text { Bacilos } \\
\text { GRAM (-) }\end{array}$ \\
\hline BAM 004 & $\begin{array}{l}\text { Crecimiento en césped, aspecto } \\
\text { traslúcido. El medio, inicialmente } \\
\text { de color miel, tornó a verde. }\end{array}$ & + & $\begin{array}{l}\text { Bacilos } \\
\text { GRAM (-) }\end{array}$ \\
\hline BAM 005 & $\begin{array}{l}\text { Colonias redondas de superficie } \\
\text { lisa y aspecto cremoso, color } \\
\text { manteca. Tamaño mediano. }\end{array}$ & + & $\begin{array}{l}\text { Cocobacilos } \\
\text { GRAM (+) }\end{array}$ \\
\hline BAM 020 & $\begin{array}{l}\text { Colonias redondas y superficie lisa, } \\
\text { bordes más claros que el centro y } \\
\text { de coloración blancuzca pálida. }\end{array}$ & + & $\begin{array}{l}\text { Bacilos } \\
\text { GRAM (-) }\end{array}$ \\
\hline BAM021 & $\begin{array}{l}\text { Colonias redondas y superficie lisa, } \\
\text { coloración blancuzca pálida. }\end{array}$ & + & $\begin{array}{c}\text { Cocobacilos } \\
\text { GRAM }(+)\end{array}$ \\
\hline BAM 023 & $\begin{array}{l}\text { Colonias redondas y pequeñas, } \\
\text { superficie lisa y aspecto cremoso } \\
\text { de coloración blancuzca pálida. }\end{array}$ & + & $\begin{array}{l}\text { Cocobacilos } \\
\text { GRAM (+) }\end{array}$ \\
\hline BAM 028 & $\begin{array}{l}\text { Colonias redondas, de superficie lisa y } \\
\text { aspecto cremoso de color manteca. }\end{array}$ & + & $\begin{array}{l}\text { Cocobacilos } \\
\text { GRAM (-) }\end{array}$ \\
\hline BAM 073 & $\begin{array}{l}\text { Crecimiento en césped, } \\
\text { aspecto traslúcido. }\end{array}$ & + & $\begin{array}{c}\text { Cocobacilos } \\
\text { GRAM }(-)\end{array}$ \\
\hline BAM 074 & $\begin{array}{l}\text { Crecimiento en césped, } \\
\text { aspecto traslúcido. }\end{array}$ & + & $\begin{array}{l}\text { Bacilos } \\
\text { GRAM (-) }\end{array}$ \\
\hline BAM 075 & $\begin{array}{l}\text { Crecimiento en césped, } \\
\text { aspecto traslúcido. }\end{array}$ & + & Cocos GRAM (-) \\
\hline BAM 076 & $\begin{array}{l}\text { Crecimiento en césped, } \\
\text { aspecto traslúcido. }\end{array}$ & + & $\begin{array}{l}\text { Bacilos } \\
\text { GRAM (-) }\end{array}$ \\
\hline BAM 077 & $\begin{array}{l}\text { Colonias redondas de superficie lisa, } \\
\text { aspecto cremoso de coloración blanca. }\end{array}$ & + & $\begin{array}{l}\text { Cocobacilos } \\
\text { GRAM }(-)\end{array}$ \\
\hline BAM 078 & $\begin{array}{l}\text { Crecimiento en césped, } \\
\text { aspecto traslúcido. }\end{array}$ & + & $\begin{array}{l}\text { Cocobacilos } \\
\text { GRAM (-) }\end{array}$ \\
\hline BAM 081 & $\begin{array}{l}\text { Crecimiento en césped, } \\
\text { aspecto traslúcido. }\end{array}$ & + & $\begin{array}{l}\text { Bacilos } \\
\text { GRAM }(-)\end{array}$ \\
\hline BAM 083 & $\begin{array}{l}\text { Crecimiento en césped, } \\
\text { aspecto traslúcido. }\end{array}$ & + & $\begin{array}{l}\text { Cocobacilos } \\
\text { GRAM (-) }\end{array}$ \\
\hline BAM 089 & $\begin{array}{l}\text { Crecimiento en césped, } \\
\text { aspecto traslúcido. }\end{array}$ & + & $\begin{array}{c}\text { Cocobacilos } \\
\text { GRAM (-) }\end{array}$ \\
\hline
\end{tabular}

Junto a los 5 aislamientos que mostraron actividad amilolítica, fueron seleccionadas otros 10 aislados: BAM003, BAM004, BAM073, BAM074, BAM075, BAM076, BAM078, BAM081, BAM083, BAM089, que no dieron un resultado concluyente en la prueba cualitativa de degradación de almidón, pero fueron capaces de crecer cubriendo toda la superficie de la placa de Petri, indicando que podrían tener la capacidad de utilizar almidón de mandioca como nutriente.

La identificación molecular de las cepas seleccionadas se realizó mediante la secuenciación del 16S rDNA amplificado por PCR y por comparación de las secuencias obtenidas con la base de datos del NCBI. Se lograron identificar a 6 de los 15 aislamientos preseleccionados como pertenecientes a los géneros Pseudomonas, Acinetobacter y Proteus.

Para dar un mayor soporte a la identificación taxonómica obtenida previamente se construyó un árbol filogenético (Figura 2) mediante un análisis de distancias utilizando el método Neighbor-Joining [20] disponible en el programa Mega X [16]. El análisis involucró 26 secuencias nucleotídicas de regiones ADNr 16S correspondiente a los aislados en estudio y algunas de las presentes en la base de datos.

En el árbol construido (Figura 2), las cepas BAM003, BAM004 y BAM028 han sido agrupadas con aquellas pertenecientes al género Pseudomonas de la familia Pseudomonadaceae con un soporte del 100\%. La cepa BAM003 mostró una agrupación consistente y con soporte del 100\% con Pseudomonas aeruginosa (NR_117678.1), mientras que BAM028 se ha agrupado con soporte del 99\% con secuencias pertenecientes a Pseudomonas putida (NR_114479.1). Las secuencias de las cepas BAM074 y BAM081 se agruparon con aquellas pertenecientes al género Proteus, familia Enterobacteriaceae y con un grupo más pequeño de secuencias de Proteus mirabilis con un soporte mayor al 90\%. Por último, BAM020 ha sido agrupada dentro de las Acinobacterias de la familia Moraxellaceae.

Estos resultados coinciden con trabajos anteriores donde se ha reportado el aislamiento de bacterias como Proteus y Pseudomonas a partir de muestras tomadas en el punto de descarga de aguas residuales de mandioca [21-23]. Adicionalmente, se considera que Pseudomonas posee un gran potencial de biorremediación cuando forman consorcios con otras especies bacterianas [17]. Bacterias del género Acinetobacter que incluye especies patogénicas y no patogénicas [24], son abundantes en ambientes naturales [25], también han sido aisladas a partir de muestras de efluentes de fábricas de almidón de mandioca y evaluadas por su eficacia en la degradación de almidón y producción de biohidrógeno [26]. 


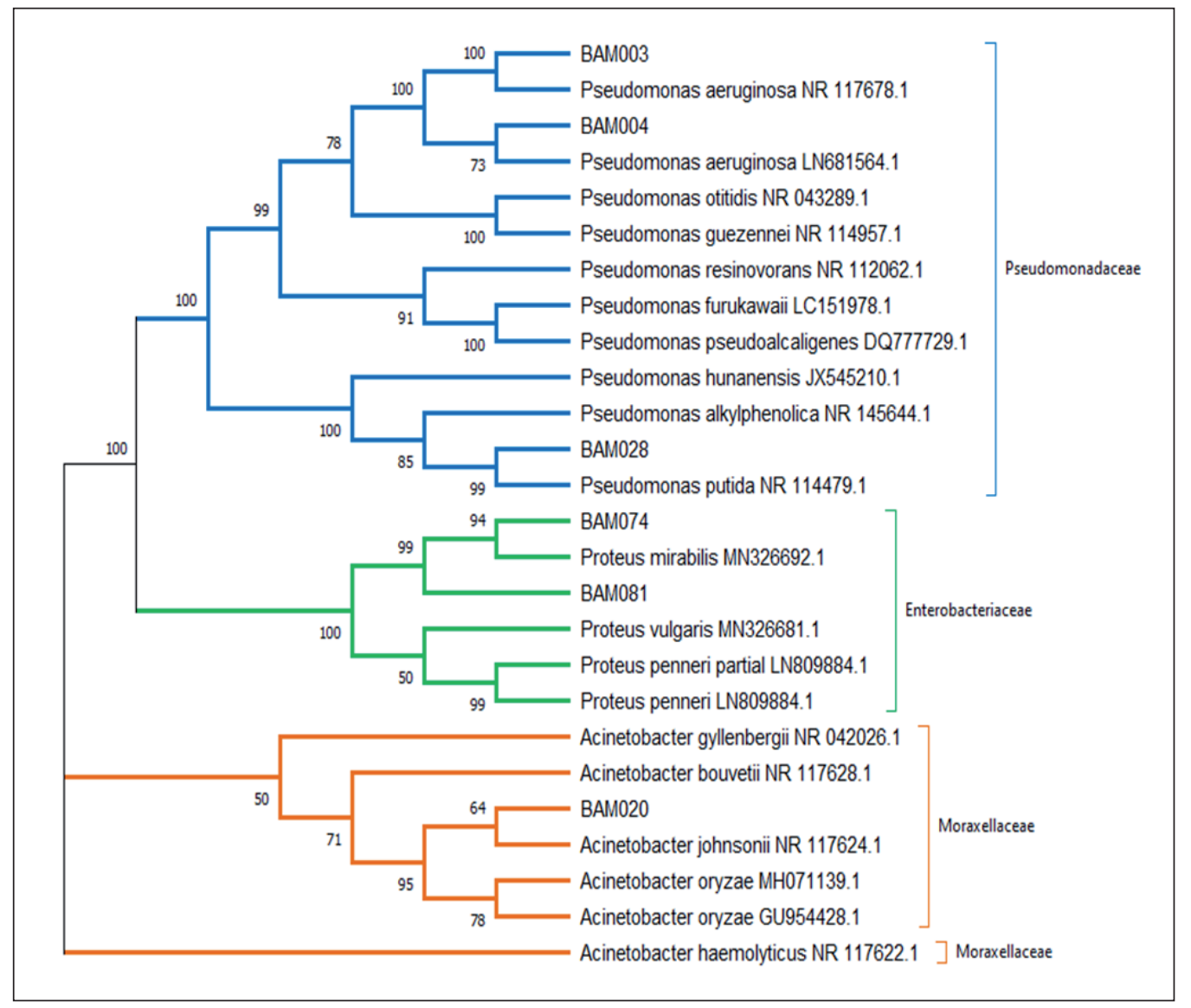

Figura 2: Relaciones filogenéticas entre las secuencias 16S rDNA. El árbol fue construido utilizando el método Neighbor-Joining. El árbol consenso se obtuvo a partir de 2000 réplicas y las distancias fueron computadas utilizando el método Máxima Verosimilitud Compuesta.

A continuación, se realizó una evaluación del crecimiento de las cepas identificadas como amilolíticas en el ensayo cualitativo. Utilizando medio mínimo suplementado con fécula de mandioca, las bacterias no superaron la fase de adaptación de crecimiento; en cambio, las cepas ensayadas mostraron un crecimiento eficiente con medio LB con $1 \%$ de almidón soluble (Figura 3), la cepa BAM077 mostró mejor desempeño cuando creció en medio suplementado con almidón, mientras que la cepa BAM005, fue la única que mostró un crecimiento más eficiente cuando creció en medio LB sin la presencia de almidón.

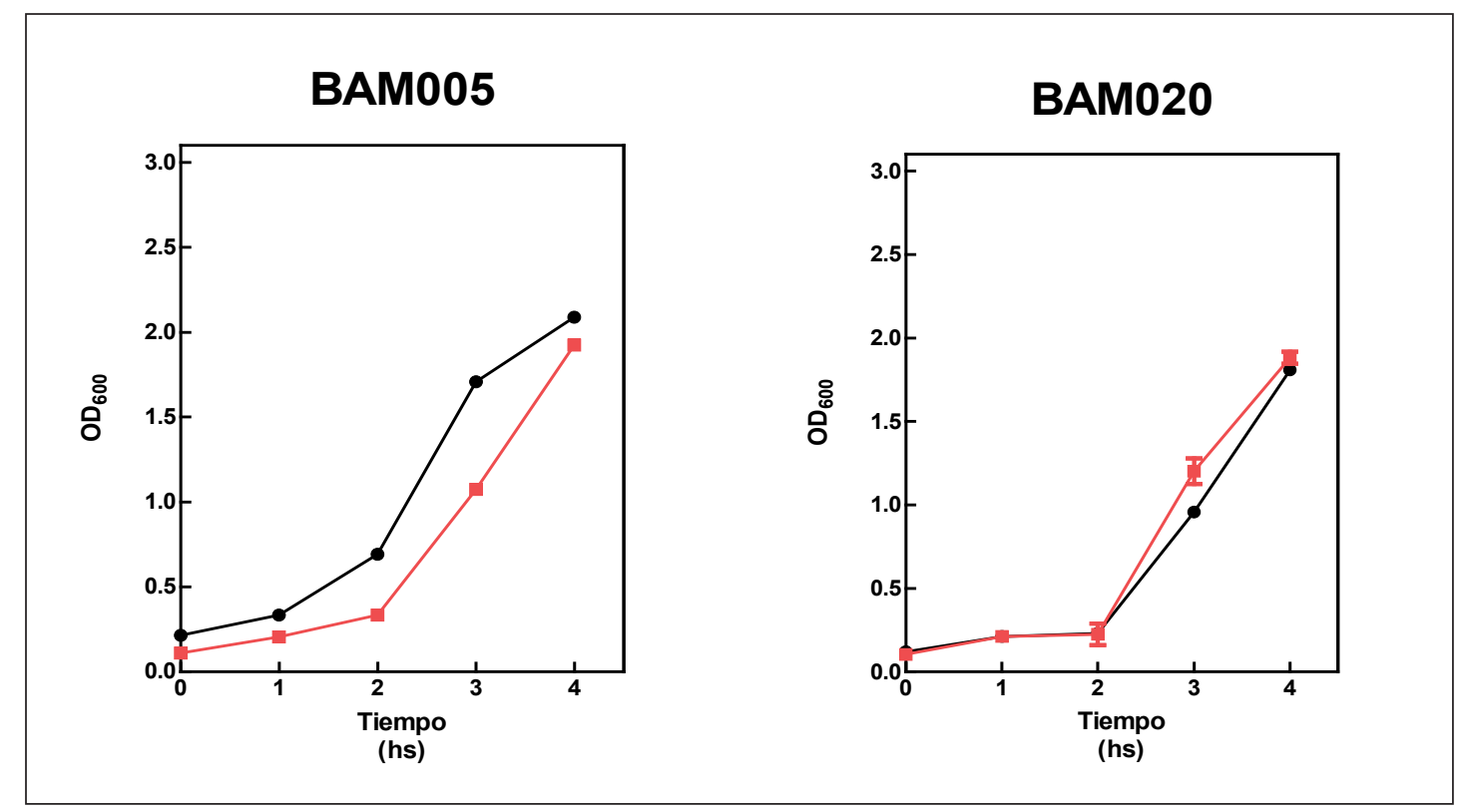




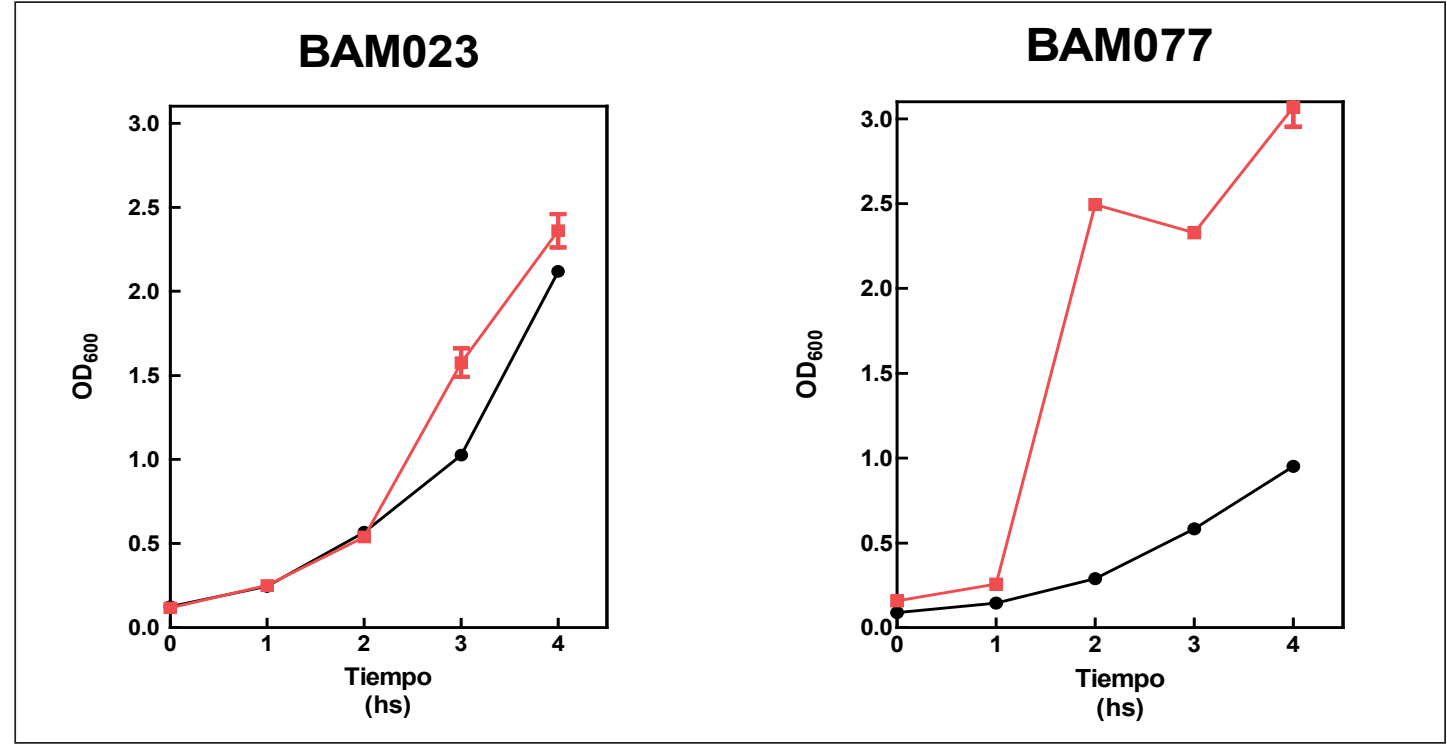

Figura 3: Curvas de crecimiento. Las bacterias seleccionadas crecieron en medio LB (línea negra) o medio LB suplementado con $1 \%$ de almidón (línea roja). A intervalos de 1 hr se midió la densidad óptica a 600nm.

Finalmente, las 15 cepas seleccionadas inicialmente fueron incubadas durante $24 \mathrm{~h}$ a $37^{\circ} \mathrm{C}$, en las placas con concentraciones crecientes de cianuro. Se visualizaron pequeñas colonias redondas de coloración celeste fluorescente con una tolerancia de hasta $20 \mathrm{mM}$ de cianuro en las inoculaciones realizadas en las posiciones 1, 2 y 7 (Figura 4), correspondientes a las cepas BAM003, BAM004 y BAM028. Ciertos microorganismos son capaces de utilizar cianuro y sus derivados como única fuente de carbono y nitrógeno, empleando una variedad de rutas para su descomposición $[27,28]$. Sin embargo, en ocasiones, la toxicidad del cianuro restringe su uso como fuente primaria de carbono $\mathrm{y}$, dado que la cantidad de nitrógeno necesaria para el crecimiento es menor que la de carbono, podría ser más fácil utilizarlo como fuente de nitrógeno en presencia de otra fuente de carbono como la glucosa. En nuestro ensayo, las cepas que crecieron en medio con cianuro pertenecen al género Pseudomonas, por lo que se presume que podrían ser capaces de utilizarlo como fuente de nitrógeno para su crecimiento. Se ha demostrado que cepas de Pseudomonas putida aisladas a partir de aguas residuales de una fábrica de mandioca han presentado tolerancia y capacidad de crecer en concentraciones de cianuro por encima de $5 \mathrm{mM}$, incrementando la tasa de eliminación en presencia de glucosa como fuente de carbono, con la formación de amoníaco y formiato como productos metabólicos finales sugiriendo una vía hidrolítica [29].

En otras investigaciones se ha demostrado la capacidad de Pseudomonas aeruginosa en la biodegradación de cianuro libre bajo condiciones alcalinas [30], por lo que su presencia y aislamiento a partir de muestras de efluentes industriales en el presente trabajo podría sugerir su potencial como biorremediador de estas aguas residuales.

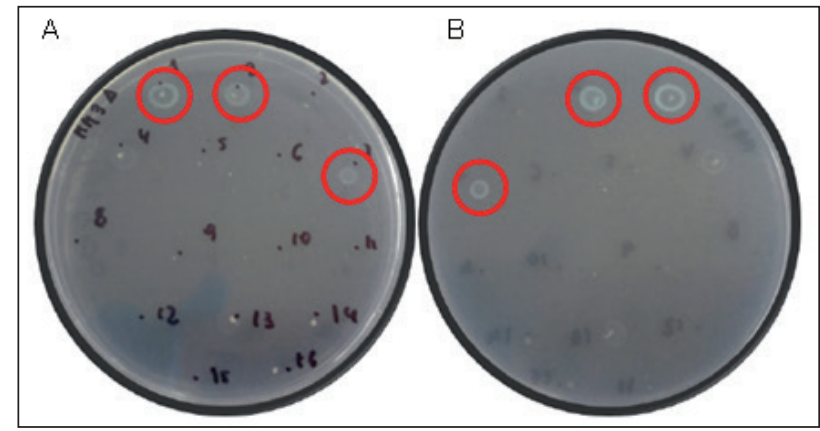

Figura 4: Tolerancia a cianuro. Crecimiento en medio mínimo con agar suplementado con glucosa $1 \%$ y cianuro $20 \mathrm{mM}$ de colonias redondas con bordes de coloración celeste fluorescente en posiciones 1, 2 y 7 correspondientes a las cepas BAM003, BAM004 y BAM028, respectivamente. (A) Reverso de la placa. (B) Anverso de la placa.

\section{Conclusiones}

La cepa BAM028 identificada como perteneciente al género Pseudomonas y cercana a la especie Pseudomonas putida, posee tanto la capacidad de degradar almidón como la de crecer en medio que contiene cianuro utilizándolo como fuente de nitrógeno. Dos de las cepas que crecen en forma de césped en las placas suplementadas con almidón, BAM003 y BAM004, cercanas a la especie Pseudomonas aeruginosa, no evidenciaron cualitativamente la capacidad de degradar almidón, pero sí pudieron crecer en presencia de cianuro.

Este estudio contribuye al conocimiento de la variedad de microorganismos que pueden ser aislados de efluentes de almidoneras industriales de la Provincia de Misiones y su potencial para ser utilizadas en la degradación de almidón y compuestos de cianuro como parte de una estrategia de biorremediación. 


\section{Conflicto de Interés}

Los autores declaran que no existe conflicto de interés

\section{Agradecimientos}

Los autores agradecen la colaboración de la planta industrial Almidonera AG. Este proyecto fue financiado por la Facultad de Ciencias Exactas, Químicas y Naturales, Universidad Nacional de Misiones (Proyecto de Investigación 16/Q650 PI).

\section{Referencias bliográficas}

1. J. A. Montagnac, C. R. Davis, and S. A. Tanumihardjo, "Nutritional value of cassava for use as a staple food and recent advances for improvement", Compr Rev Food Sci Food Saf, vol. 8, pp. 181-194, 2009.

2. E. Corradini and M. Lazzaro, "Mandioca, planificación y calidad”, Revista Alimentos Argentinos, vol. 66, pp. 78, 2015.

3. M. Lázzaro, E. Corradini, A. M. Cherasco, and F. De Haro, "Informe Proyecto De Asistencia Integral Para El Agregado De Valor En Agroalimentos (PROCAL)'” 2015.

4. A. S. Sánchez, Y. L. Silva, R. A. Kalid, E. Cohim, and E. A. Torres, "Waste bio-refineries for the cassava starch industry: New trends and review of alternatives”, Renew Sust Energ Rev, vol. 73, pp. 1265-1275, 2017.

5. L. Sun, S. Wan, Z. Yu, Y. Wang, and S. Wang, "Anaerobic biological treatment of high strength cassava starch wastewater in a new type up-flow multistage anaerobic reactor”, Biores Tech, vol. 104, pp. 280-288, 2012.

6. A. Fukushima, M. A. Nicoletti, A. J. Rodrigues, C. Pressutti, J. Almeida, T. Brandão, R. K. Ito, L. A. B. Leoni, and H. D. S. Spinosa, "Cassava flour: quantification of cyanide content", Food Nutr Sci, vol. 7, pp. 592, 2016.

7. M. Sharma, Y. Akhter, and S. Chatterjee, "A review on remediation of cyanide containing industrial wastes using biological systems with special reference to enzymatic degradation”, World J Microb Biotech, vol. 35, pp. $70,2019$.

8. S. Kuppusamy, K. Venkateswarlu, M. Megharaj, N. Vasudevan, and Y. B. Lee, "Biostimulation and Bioaugmentation: Modern Strategies for the Successful Bioremediation of Contaminated Environments", in The Handbook of Environmental Remediation, 2020, pp. 299-330.

9. R. Kumar, S. Saha, S. Dhaka, M. B. Kurade, C. U. Kang, S. H. Baek, and B.-H. Jeon, "Remediation of cyanide-contaminated environments through microbes and plants: a review of current knowledge and future perspectives", Geosys Eng, vol. 20, pp. 28-40, 2017.

10. M. P. D. Nair, G. Padmaja, and S. N. Moorthy, "Biodegradation of cassava starch factory residue using a combination of cellulases, xylanases and hemicellulases", Biomass Bioenerg, vol. 35, pp. 1211-1218, 2011.
11. S. E. Agarry and C. N. Owabor, "Evaluation of microbial systems for biotreatment of cassava mill waste water in Nigeria: biodegradation of cyanide”, Int J Environ Eng, vol. 4, pp. 315-323, 2012.

12. S. Kandasamy, B. Dananjeyan, and K. Krishnamurthy, "Biodegradation of cyanide and starch by individual bacterial strains and mixed bacterial consortium isolated from cassava sago wastewater", Res J Chem Environ, vol. 18, pp. 13-18, 2014.

13. E. W. Koneman and S. Allen, Diagnóstico Microbiológico: Texto y Atlas En Color. Ed. Médica Panamericana, 2008.

14. C. S. Hoffman and F. Winston, "A ten-minute DNA preparation from yeast efficiently releases autonomous plasmids for transformaion of Escherichia coli”, Gene, vol. 57, pp. 267-272, 1987.

15. D. J. Lane, " $16 S / 23 S$ rRNA sequencing, ” in Nucleic acid techniques in bacterial systematics, 1991, pp. 115-175.

16. S. Kumar, G. Stecher, M. Li, C. Knyaz, and K. Tamura, "MEGA $X$ : molecular evolutionary genetics analysis across computing platforms", Mol Biol Evol, vol. 35, pp. 1547-1549, 2018.

17. K. E. Enerijiofi, F. O. Ekhaise, and I. E. Ekomabasi, "Biodegradation potentials of cassava mill effluent (CME) by indigenous microorganisms", J Appl Sci Env Manag, vol. 21, pp. 1029-1034, 2017.

18. J. A. Amao, M. Barooah, and P. F. Omojasola, "Comparative 16S rDNA metagenomics study of two samples of cassava peel heap from Nigeria and India”, 3 Biotech, vol. 9, pp. 418, 2019.

19. M. A. Naidu and P. Saranraj, "Bacterial amylase: a review", Int J Pharm Biol Arch, vol. 4, pp. 274-287, 2013.

20. N. Saitou and M. Nei, "The neighbor-joining method: a new method for reconstructing phylogenetic tree”, Mol Biol Evol, vol. 4, pp. 406-425, 1987.

21. S. C. Izah, E. B. Enaregha, and J. O. Epidi, "Changes in insitu water characteristics of cassava wastewater due to the activities of indigenous microorganisms", MOJ Toxicol, vol. 5, pp. 78-81, 2019.

22. M. Omotioma, G. O. Mbah, I. J. Akpan, and O. B. Ibezim, "Impact assessment of cassava effluents on barika stream in Ibadan, Nigeria”, Int J Environ Sci Managem Eng Res, vol. 2, pp. 50-56, 2013.

23. R. N. Okechi, C. E. Ihejirika, N. A. Chiegboka, E. I. Chukwura, and I. J. Ibe, "Evaluation of the effects of cassava mill effluent on the microbial populations and physicochemical parameters at different soil depths", Int J Biosci, vol. 2, pp. 139-45, 2012.

24. V. de Berardinis, M. Durot, J. Weissenbach, and M. Salanoubat, "Acinetobacter baylyi ADP1 as a model for metabolic system biology, ” Curr Op Microbiol, vol. 12, pp. 568576, 2009.

25. A. Al Atrouni, M.-L. Joly-Guillou, M. Hamze, and M. Kempf, "Reservoirs of non-baumannii Acinetobacter species", Frontiers Microbiol, vol. 7, pp. 49, 2016. 
26. L. Ayoub, "Biohydrogen generation by dark fermentation of starch using bacteria isolated from tapioca wastewater", in Faculty Sciences. Malasya: University of Technology 2018.

27. N. V. Grigor'eva, T. F. Kondrat'eva, E. N. Krasil'nikova, and G. I. Karavaiko, "Mechanism of cyanide and thiocyanate decomposition by an association of Pseudomonas putida and Pseudomonas stutzeri strains", Microbiol, vol. 75, pp. 266-273, 2006.

28. K. D. Chapatwala, G. R. V. Babu, O. K. Vijaya, K. P. Kumar, and J. H. Wolfram, "Biodegradation of cyanides, cyanates and thiocyanates to ammonia and carbon dioxide by immobilized cells of Pseudomonas putida”, J Ind Microbiol Biotech, vol. 20, pp. 28-33, 1998.

29. S. Kandasamy, B. Dananjeyan, K. Krishnamurthy, and G. Benckiser, "Aerobic cyanide degradation by bacterial isolates from cassava factory wastewater”, Brazilian J Microbiol, vol. 46, pp. 659-666, 2015.

30. L. Mekuto, S. K. O. Ntwampe, M. Kena, M. T. Golela, and O. S. Amodu, "Free cyanide and thiocyanate biodegradation by Pseudomonas aeruginosa STK 03 capable of heterotrophic nitrification under alkaline conditions", 3 Biotech, vol. 6, pp. 6, 2016. 